\title{
Visualization of Oxide Ionic Diffusion at SOFC Cathode/Electrolyte Interfaces by Isotope labeling Techniques
}

\author{
Teruhisa Horita, Mina Nishi, Taro Shimonosono, Haruo Kishimoto, Katsuhiko Yamaji, \\ Manuel E. Brito ${ }^{a}$, and Harumi Yokokawa ${ }^{b}$ \\ Fuel Cell Materials Group, Energy Technology Research Institute, \\ National Institute of Advanced Industrial Science and Technology (AIST) \\ AIST Central 5, Higashi 1-1-1. Tsukuba, Ibaraki 305-8565 JAPAN
}

Email: t.horita@aist.go.jp

Corresponding author: Teruhisa HORITA, E-mail: thorita@ aist.go.jp

Current affiliation:

${ }^{\text {a }}$ Fuel Cell Nanomaterials Center, Yamanashi University, 6-43 Miyamae-cho, Kofu, Yamanashi 400-0021, Japan

${ }^{\mathrm{b}}$ Institute of Industrial Science, The University of Tokyo, Komaba 4-6-1, Meguro-Ku, Tokyo 153-8505, Japan

\begin{abstract}
Oxygen isotopic labeling $\left({ }^{16} \mathrm{O} /{ }^{18} \mathrm{O}\right.$ exchange) technique has been applied to visualize the oxide ionic diffusion in cathodic polarized sample at $\mathrm{La}_{0.6} \mathrm{Sr}_{0.4} \mathrm{Co}_{0.2} \mathrm{Fe}_{0.8} \mathrm{O}_{3-\mathrm{d}} / \mathrm{Gd}_{0.1} \mathrm{Ce}_{0.9} \mathrm{O}_{2-\mathrm{x}}$ $(\mathrm{GDC}) / \mathrm{Y}_{0.15} \mathrm{Zr}_{0.85} \mathrm{O}_{2-\mathrm{y}}(\mathrm{YSZ})$ interfaces. The depth profiles of secondary ion mass spectrometry (SIMS) have been applied to analyze the distribution of ${ }^{18} \mathrm{O}$ and metal oxide ions precisely. ${ }^{18} \mathrm{O}$ concentration peak was identified only under cathodic polarization with a constant current density of $0.071 \mathrm{Acm}^{-2}$ at $973 \mathrm{~K}$ under ${ }^{18} \mathrm{O}_{2}$ atmosphere. The ${ }^{18} \mathrm{O}$ peak position was corresponded to the $\mathrm{Sr}$ condensed zone where $\mathrm{SrZrO}_{3}$ was formed at the GDC/YSZ interfaces. The $\mathrm{SrZrO}_{3}$ formation and the ${ }^{18} \mathrm{O}$ concentration profile pile-up are correlated each other due to the increase of ${ }^{18} \mathrm{O}$ incorporation and retention of ${ }^{18} \mathrm{O}^{2-}$ diffusion at the interfaces under cathodic polarization.
\end{abstract}

Key words: SOFC, isotope labeling, cathode, SIMS, depth profiles 


\section{Introduction}

One of the key functions of Solid Oxide Fuel Cells (SOFCs) is the ionization and reduction of oxygen molecules to oxide ions $\left(\mathrm{O}_{2}+4 \mathrm{e}^{-} \rightarrow 2 \mathrm{O}^{2-}\right)$ at the cathode/electrolyte interfaces. Among many internal resistances of SOFCs, the ionization of oxygen and/or diffusion of oxide ions show relatively large resistance values. To promote these reaction rates effectively, ionization and diffusion mechanism should be clarified at the $\mathrm{La}_{1-\mathrm{x}} \mathrm{Sr}_{\mathrm{x}} \mathrm{Co}_{1-\mathrm{y}} \mathrm{Fe}_{\mathrm{y}} \mathrm{O}_{3-\mathrm{d}}$ (LSCF) cathode $/ \mathrm{Gd}_{2} \mathrm{O}_{3}-\mathrm{CeO}_{2}$ (GDC) interlayer/ $\mathrm{Y}_{2} \mathrm{O}_{3}-\mathrm{ZrO}_{2}$ (YSZ) electrolyte interfaces. So far, a number of studies have been made on the clarification of cathode reaction mechanism [1-7]. Typical analytical methods for the oxygen reduction mechanism are the comparison between the electrode reaction rates and the partial pressure of oxygen. This method can show some important features of reaction mechanism with relation to reaction areas [2-7]. However, the method sometimes has a difficulty in determining the active sites distributions and diffusion paths at the interfaces.

To clarify the oxygen ionization and diffusion paths directly, we have applied the isotope labeling technique by using stable isotope oxygen $\left({ }^{18} \mathrm{O}_{2}\right)$ under fuel cell reactions [8-10]. We have succeeded in visualizing the active sites of oxygen reduction and diffusion paths of oxide ions at the practical flat-tube SOFC cell-stacks. During the analysis of ${ }^{18} \mathrm{O}$ diffusion, we found that the ${ }^{18} \mathrm{O}$-concentration peaks appeared at the cathode/interlayer/electrolyte interfaces only under fuel cell reaction. The ${ }^{18} \mathrm{O}$ peak areas were almost proportional to the current densities passing through the electrolyte [10]. The formation of ${ }^{18} \mathrm{O}$ peak in the SIMS images has a correlation with the formation of different ${ }^{18} \mathrm{O}$-diffusion layers at the interfaces. The GDC interlayer has an advantage to prevent chemical reaction between LSCF and YSZ, while small amounts of Sr- diffusion and $\mathrm{Ce}-\mathrm{Zr}$ solid solution formation have been the major issues for applying the GDC interlayer [5]. In our previous study, the metal oxide ion $\left(\mathrm{M}^{16} \mathrm{O}^{-}\right)$ distribution has not been clarified due to low signal intensities in the SIMS imaging mode [9, 10]. To overcome the difficulty of secondary ion detection at the interfaces, SIMS depth profiles have been applied for small cell samples with relatively high signal intensities in this study. A new glass ${ }^{16} \mathrm{O} /{ }^{18} \mathrm{O}$ exchange system was fabricated for observing the ${ }^{18} \mathrm{O}$ diffusion under cathodic polarization. We report the relationship between ${ }^{18} \mathrm{O}$ diffusion and the metal oxide ion distributions at the interfaces.

\section{Experimental}

\subsection{Samples and ${ }^{16} \mathrm{O} /{ }^{18} \mathrm{O}$ exchange}


The cathode/interlayer/electrolyte samples were purchased from the Nex Tech Materials, Ltd. USA. The cathode, interlayer, electrolyte, counter electrode materials were $\mathrm{La}_{0.6} \mathrm{Sr}_{0.4} \mathrm{Co}_{0.2} \mathrm{Fe}_{0.8} \mathrm{O}_{3-\mathrm{d}}$ (LSCF), $\mathrm{Gd}_{0.2} \mathrm{Ce}_{0.8} \mathrm{O}_{1.9}$ (GDC), $8 \mathrm{Y}_{2} \mathrm{O}_{3}-92 \mathrm{ZrO}_{2}$ (8YSZ), and Pt-paste, respectively. The thickness and diameter of electrolyte was $\sim 200 \mu \mathrm{m}$ and $20 \mathrm{~mm}$, respectively. The electrolyte supported cells were tested in air $/{ }^{18} \mathrm{O}_{2}$ atmosphere (the geometrical area of LSCF cathode is $0.28 \mathrm{~cm}^{2}$ ). Due to the limitation of hydrogen gas usage in glass reactor in this experiment, air was flowed at the Pt-counter electrode side as shown in Fig.1. Pt-mesh current collector was attached on the LSCF porous cathode before cell tests by firing at 1323 $\mathrm{K}$ for $5 \mathrm{~h}$ in air. The ${ }^{16} \mathrm{O} /{ }^{18} \mathrm{O}$ exchange experiment was conducted by using glass tube reactor under cathodic polarization. Initially, air $\left[p\left(\mathrm{~N}_{2}\right)=79 \mathrm{kPa}, p\left(\mathrm{O}_{2}\right)=21 \mathrm{kPa}\right]$ was flowed for both side of the cell before the ${ }^{16} \mathrm{O} /{ }^{18} \mathrm{O}$ exchange, and electrochemical measurements were conducted at 973-1173 K. The applied constant current was $71 \mathrm{mAcm}^{-2}$ between LSCF and Pt counter electrode in cathodic direction. The oxygen atmosphere was quickly switched from air to ${ }^{18} \mathrm{O}_{2}$ pure gas by using 6 way valves under constant cathodic current. The monitored voltage at cathode was about $-250 \mathrm{mV} \sim-300 \mathrm{mV}$ versus the reference electrode during experiments. The exchange gas pressure of oxygen was $p\left({ }^{18} \mathrm{O}_{2}\right) \sim 50 \mathrm{kPa}$ with a purity above 95 vol\%. The duration time for the ${ }^{16} \mathrm{O} /{ }^{18} \mathrm{O}$ exchange was $180 \mathrm{~s}$. A glass seal was applied to avoid the ${ }^{18} \mathrm{O}_{2}$ leakage (the ${ }^{18} \mathrm{O}_{2}$ pressure change was kept within $5 \%$ ) during ${ }^{16} \mathrm{O} /{ }^{18} \mathrm{O}$ exchange.

In ${ }^{18} \mathrm{O}_{2}$ atmosphere, dissociative adsorption of ${ }^{18} \mathrm{O}_{2}$ occurs on the surface of cathode or interlayer. Then, the exchange reaction occurs between adsorption ${ }^{18} \mathrm{O}_{\mathrm{ad}}$ and ${ }^{16} \mathrm{O}$ in the lattice of cathode and/or interlayer with electronic charge transfer in the following reaction [11-17]:

${ }^{18} \mathrm{O}_{2}(\mathrm{~g}) \rightarrow 2{ }^{18} \mathrm{O}_{\mathrm{ad}}$ (oxygen adsorption and dissociation)

${ }^{18} \mathrm{O}_{\mathrm{ad}}+2 \mathrm{e}^{-} \rightarrow{ }^{18} \mathrm{O}^{2-} \quad$ (charge transfer)

${ }^{18} \mathrm{O}^{2-} \leftrightarrow{ }^{16} \mathrm{O}^{2-}$ (isotopic exchange on solid surface region)

The driving force of isotopic exchange reaction is the gradient of isotopic oxygen concentration between gas phase and solids. In addition to the isotope oxygen gradient, the applied current promotes the ${ }^{18} \mathrm{O}$ incorporation into cathode-electrolyte by the electrochemical reaction (promotion of reaction of (2)). In such a dynamic condition, diffusion of ${ }^{18} \mathrm{O}$ is enhanced by the electrochemical pumping of ${ }^{18} \mathrm{O}^{2-}$ through the electrolyte. The current density $(J)$ is directly related to the numbers of oxide ions $\left(n\left({ }^{18} \mathrm{O}^{2-}\right)\right)$ passing through the electrolyte, $n\left({ }^{18} \mathrm{O}^{2-}\right)=J / 2 F\left(F\right.$ is the Faraday constant and $n\left({ }^{18} \mathrm{O}^{2-}\right)=1.04 \times 10^{-7} \mathrm{mols}^{-1} \mathrm{~cm}^{-2}$ in this condition). 


\subsection{SIMS analysis}

After the ${ }^{16} \mathrm{O} /{ }^{18} \mathrm{O}$ exchange, the depth profiles of ${ }^{18} \mathrm{O}$ and metal-oxide ions were analyzed by secondary ion mass spectrometry (SIMS, AMETEK-Cameca imf-5f). A primary ion beam was positive $\mathrm{Cs}^{+}$(accelerating voltage was $10 \mathrm{kV}$, primary current of $3 \times 10^{-8} \mathrm{~A}$ ) and the negative secondary ions $\left({ }^{16} \mathrm{O}^{-},{ }^{18} \mathrm{O}^{-}, \mathrm{M}^{16} \mathrm{O}^{-}\right.$, where $\mathrm{M}$ indicates metal) were collected within a raster of $100 \times 100 \mu^{2}$. Relative intensities of secondary ions $\left[C_{180}(x)=I_{180}(x) /\left\{I_{160}(x)+I_{180}(x)\right\}, R_{M 160}(x)=I_{M 160} / I_{160}(x)\right.$, where $I_{160}(x), I_{180}(x), I_{M 160}(x)$, are the secondary ion intensities of ${ }^{16} \mathrm{O}^{-},{ }^{18} \mathrm{O}^{-}$, and $\mathrm{M}^{16} \mathrm{O}^{-}$at depth of $x$, respectively] were analyzed as a function of depth. Diffusion properties of ${ }^{18} \mathrm{O}$ and metal oxide species were observed at the cathode/interlayer/electrolyte interfaces. Relative intensities of secondary ions can show the relative change of secondary ions to avoid the effects of porosity of samples at the interfaces for analyzing the diffusion profiles.

\section{Results}

\subsection{Microstructures of LSCF/GDC/YSZ interfaces}

Fig. 2 shows backscattered scanning electron microscope (SEM) images of LSCF/GDC/YSZ interfaces before (a) and after the ${ }^{16} \mathrm{O} /{ }^{18} \mathrm{O}$ exchange under cathodic polarization (b). The SEM images at the LSCF cathode show a porous structure which indicates enough space for oxygen gas diffusion through the LSCF structures. The microstructure of GDC interlayer is also porous with a connection of dense YSZ. There is a reaction layer between GDC and YSZ: this can be the Sr-containing compounds that will be discussed in the latter section. After the ${ }^{16} \mathrm{O} /{ }^{18} \mathrm{O}$ experiments, the grain size of LSCF and Sr-compounds layer became larger and thicker than those before the experiments. The change in the microstructures is caused by the heat treatments (such as Pt-mesh attachments) and cathodic polarization. Especially, the reaction layer was mainly formed during the Pt-mesh attachment process due to the relative high sintering temperature. Cathodic polarization can increase the local temperature due to current passage. A more information on elemental distribution will be discussed in the latter section.

\subsection{Electrochemical performance of examined sample}

Fig.3 shows current density -voltage $(J-E)$ characteristics of LSCF/GDC/YSZ samples operated at different temperatures in air. Although the $J-E$ curves are not always linear at all the currents and temperature ranges, the resistance of cathode was roughly 
calculated at the LSCF/GDC interface: the resistances of the cell were $\sim 4 \Omega \mathrm{cm}^{2}, \sim 1 \Omega \mathrm{cm}^{2}$, and $\sim 0.5 \Omega \mathrm{cm}^{2}$ at $973 \mathrm{~K}, 1073 \mathrm{~K}$, and $1173 \mathrm{~K}$, respectively. These values are almost consistent with the AC impedance measurements: the measured ohmic and polarization resistances at $973 \mathrm{~K}$ were $1.3 \Omega$ and $2.6 \Omega$, respectively. The ${ }^{16} \mathrm{O} /{ }^{18} \mathrm{O}$ exchange was conducted at a constant cathodic current of $-0.071 \mathrm{Acm}^{-2}$ at $973 \mathrm{~K}$. The measured voltage between LSCF cathode and Pt-reference was $-0.3 \mathrm{~V}$ in air. Due to the change of oxygen partial pressures, the measured voltage during the exchange experiment was lower than $-0.25 \mathrm{~V}$.

\subsection{SIMS depth profiles at cathode/interlayer/electrolyte interfaces}

Fig.4 shows SIMS depth profiles of LSCF-cathode/GDC-interlayer/YSZ-electrolyte interfaces after the ${ }^{16} \mathrm{O} /{ }^{18} \mathrm{O}$ exchange under cathodic polarization at $973 \mathrm{~K}$. The distribution of ${ }^{18} \mathrm{O}$ concentration $\left[C_{180}(x)=I_{180}(x) /\left\{I_{180}(x)+I_{160}(x)\right\}\right]$ is plotted in Fig.4(a). In LSCF cathode, the ${ }^{18} \mathrm{O}$ concentration shows an increase trend towards the cathode/interlayer interface ( $C_{180} \approx 0.5$ at surface and $C_{180} \approx 0.7$ at the cathode/interlayer interface). This indicates the difference of ${ }^{18} \mathrm{O}$ incorporation amounts in the LSCF cathode under cathodic polarization: ${ }^{18} \mathrm{O}^{2-}$ ionic current and ${ }^{18} \mathrm{O}$ incorporation can be enhanced close to the LSCF/GDC interface region. At the GDC-interlayer, ${ }^{18} \mathrm{O}$-concentration decreases due to relatively fast ${ }^{18} \mathrm{O}^{2-}$ diffusion through the porous GDC. At the GDC/YSZ-electrolyte interface region, ${ }^{18} \mathrm{O}$ concentration peak is found. This suggests a condensation of ${ }^{18} \mathrm{O}$ in the solid materials during the flow of ${ }^{18} \mathrm{O}^{2-}$. For the metal oxide ion distribution (in Fig.4(b), $R_{M 160}(x)$ ), peaks of $R_{\mathrm{Ce} 16 \mathrm{O}}$ and $R_{\mathrm{Sr} 16 \mathrm{O}}$ are identified around the cathode/interlayer/electrolyte interfaces. A peak of $R_{\mathrm{Ce} 16 \mathrm{O}}$ corresponds to the GDC-interlayer between LSCF and YSZ. A peak of $R_{\mathrm{Sr} 16 \mathrm{O}}$ can be the Sr-containing compounds (such as $\mathrm{SrZrO}_{3}$ ) formation at the GDC/YSZ interface. Heat treatments (attaching of Pt-mesh and pt-paste) of the samples can mainly affect the distribution of metal oxide ions.

In order to analyze the metal oxide ions distribution and ${ }^{18} \mathrm{O}$ diffusion at the interfaces more precisely, the diffusion profiles of ${ }^{18} \mathrm{O}, \mathrm{Ce}^{16} \mathrm{O}, \mathrm{Sr}^{16} \mathrm{O}$, and $\mathrm{Zr}^{16} \mathrm{O}$ were compared at the LSCF/GDC/YSZ interfaces between cathodic polarization and non-polarization in Fig.5. In Fig.5(a), a distinct ${ }^{18} \mathrm{O}$ peak was identified around the GDC/YSZ interface region under polarization $\left(J=-0.071 \mathrm{Acm}^{-2}\right)$ while no peaks under non-polarized condition. Metal oxide ion distributions were plotted in Fig.5(b) and Fig.5(c). The distributions of metal oxide ions are almost the same between polarization and non-polarized conditions except for $\mathrm{Sr}^{16} \mathrm{O}$. The $\mathrm{Sr}^{16} \mathrm{O}$ peak shows the thicker distribution at polarization than 
that at non-polarized condition (Fig.5(c)). The ${ }^{18} \mathrm{O}$ peak position and $\mathrm{Sr}^{16} \mathrm{O}$ peak position are well consistent with each other under polarization. Therefore, ${ }^{18} \mathrm{O}$ peak formation is related to the formation of Sr-compounds such as $\mathrm{SrZrO}_{3}$. For both cathodic and non-cathodic polarization conditions, ${ }^{18} \mathrm{O}$ drops are observed in the ${ }^{18} \mathrm{O}$ diffusion profiles at the $\mathrm{GDC} / \mathrm{SrZrO}_{3}$ interface region. This indicates that a slow ${ }^{18} \mathrm{O}$ diffusion layer formation around this interfaces, such as $\mathrm{SrZrO}_{3}$ and $\mathrm{Ce}-\mathrm{Zr}$ solid solution.

\subsection{Elemental distribution maps at the interfaces}

To confirm the elemental distribution at the interfaces precisely, energy dispersive X-ray spectroscopy (EDX) analysis was made at the LSCF-cathode/GDC-interlayer/YSZ-electrolyte interfaces after the ${ }^{16} \mathrm{O} /{ }^{18} \mathrm{O}$ exchange under cathodic polarization (Fig.6). A thick Sr-containing (mainly $\mathrm{SrZrO}_{3}$ ) layer is found between GDC and YSZ layers. A significant amount of Sr can be diffused from LSCF through the GDC interlayer to form such reaction products. $\mathrm{La}, \mathrm{Co}$, and $\mathrm{Fe}$ are also identified at the Sr-containing reaction zone and these products will be discussed in the future. Small amounts of Ce can be diffused from GDC to YSZ, which formed the Ce-Zr solid solution at the $\mathrm{GDC} / \mathrm{SrZrO}_{3} / \mathrm{YSZ}$ interfaces.

\section{Discussion}

\subsection{Sr-diffusion and peak formation of ${ }^{18} \mathrm{O}$ at the $\mathrm{GDC} / \mathrm{SrZrO}_{3} / \mathrm{YSZ}$ interfaces}

The SIMS depth profiles of ${ }^{18} \mathrm{O}$ were firstly examined at the single cell of LSCF/GDC/YSZ interfaces under cathodic polarization as shown in Fig.4 and Fig.5: ${ }^{18} \mathrm{O}$-concentration peak was formed only under cathodic polarization $\left(J=-0.07 \mathrm{Acm}^{-2}\right)$ at the GDC/YSZ interfaces where $\mathrm{SrZrO}_{3}$ was formed. $\mathrm{SrZrO}_{3}$ formation is caused by a fast $\mathrm{Sr}$ diffusion through GDC-interlayer mainly during the heat treatments (Pt attaching process). Cathodic polarization can affect the $\mathrm{SrZrO}_{3}$ formation by the local heating effects and the promotion of cation diffusion. Some authors pointed out that $\mathrm{Sr}$ in LSCF was relatively unstable and Sr-segregation occurs by the electrochemical effects [18, 19]. This result supports the previous results, and we will report these effects in the future.

The formation mechanism of ${ }^{18} \mathrm{O}$ peak at the interface $[9,10]$ was considered. One possibility is the enhancement of ${ }^{18} \mathrm{O}$ incorporation under cathodic polarization at the $\mathrm{SrZrO}_{3}$ dense layer (from Fig5 and Fig.6). Since ${ }^{18} \mathrm{O}_{2}$ gas diffusion and bulk diffusion of ${ }^{18} \mathrm{O}^{2-}$ though the LSCF-GDC are enhanced under cathodic polarization, the amounts of ${ }^{18} \mathrm{O}$ incorporation is 
the higher under cathodic polarization at the porous $\mathrm{GDC} /$ dense $\mathrm{SrZrO}_{3}$ interface. Voltage assisted ${ }^{18} \mathrm{O}$ diffusion through the YSZ has been examined in the previous work [20], which can change the ${ }^{18} \mathrm{O}$ diffusion profiles. This study can show such effects at the LSCF/GDC/YSZ interfaces. Although the SIMS signal intensity can be influenced by the microstructure at the porous GDC/dense $\mathrm{SrZrO}_{3}$ interfaces, the ratio of SIMS signals can be minimized such a microstructure effect on the distribution of ${ }^{18} \mathrm{O}$ and metal oxide ions. Another possibility is the retardation of ${ }^{18} \mathrm{O}^{2-}$ diffusion at the $\mathrm{GDC} / \mathrm{SrZrO}_{3} / \mathrm{YSZ}$ interface region. Since the $\mathrm{SrZrO}_{3}$ layer or $\mathrm{Ce}-\mathrm{Zr}$ solid solution poses the lower ${ }^{18} \mathrm{O}^{2-}$ diffusivity than YSZ, pumped ${ }^{18} \mathrm{O}^{2-}$ through GDC stayed around the $\mathrm{SrZrO}_{3} / \mathrm{YSZ}$ interface which may increase the ${ }^{18} \mathrm{O}$ concentration and pile up the ${ }^{18} \mathrm{O}$ profiles at the $\mathrm{SrZrO}_{3} / \mathrm{YSZ}$ interface.

\section{$4.2{ }^{18} \mathrm{O}$ diffusion profiles at the LSCF cathode}

The diffusion profiles of ${ }^{18} \mathrm{O}$ in LSCF cathode showed relatively flat for both cathodic polarization and non-polarization. This indicates that the surface ${ }^{16} \mathrm{O} /{ }^{18} \mathrm{O}$ exchange occurred smoothly and diffusion of ${ }^{18} \mathrm{O}^{2-}$ thorough the porous LSCF [4, 17]. A slight increase of ${ }^{18} \mathrm{O}$ concentration was observed from surface towards the LSCF/GDC interface under cathodic polarization, while constant ${ }^{18} \mathrm{O}$ concentration under non-polarization. This indicates that an increase of ${ }^{18} \mathrm{O}$ incorporation amounts close to the LSCF/GDC under polarization due to the increase of oxygen vacancies by the cathodic polarization (reducing oxygen partial pressures). The apparent ${ }^{18} \mathrm{O}$ concentration values in LSCF $\left(C_{18 \mathrm{O}}=0.5-0.7\right)$ are relatively higher than those in the previous study $\left(C_{180} \sim 0.07\right)[9,10]$. If we assume the diffusion coefficient of ${ }^{18} \mathrm{O}^{2-}$ are the same between bulk and porous LSCF cathode [16, 17], the apparent surface oxygen exchange coefficient $\left(k^{\prime}\right)$ of overall porous LSCF is estimated: this is not the same value of surface oxygen exchange rates for the bulk materials, although it roughly indicates the reaction rates for porous LSCF. An apparent surface oxygen exchange coefficient $\left(k^{\prime}\right)$ value of porous LSCF is $k^{\prime}=1 \times 10^{-4} \mathrm{cms}^{-1}$, which is two order of magnitude higher compared with the reported bulk LSCF [17]: $D=5 \times 10^{-7} \mathrm{~cm}^{2} \mathrm{~s}^{-1}$ and $k=3 \times 10^{-6} \mathrm{~cm}^{2} \mathrm{~s}^{-1}$. Since the grain size of LSCF cathode is relatively large in this study, oxygen gas diffusion and grain boundary of LSCF porous cathode can affect the surface ${ }^{16} \mathrm{O} /{ }^{18} \mathrm{O}$ exchange properties. Especially, the ${ }^{18} \mathrm{O}^{2-}$ grain boundary diffusion coefficient in LSCF can affect the diffusion profiles, which may lead to incorrect k'-value in LSCF. Also, Sr depletion in LSCF can reduce the ${ }^{18} \mathrm{O}^{2-}$ diffusivity and change the $k / D$ ratio. A precise analysis will be made in the future work. 


\section{Conclusion}

Isotopic oxygen exchange technique under cathodic polarization was firstly examined at $\mathrm{La}_{0.6} \mathrm{Sr}_{0.4} \mathrm{Co}_{0.2} \mathrm{Fe}_{0.8} \mathrm{O}_{3-\mathrm{d}}(\mathrm{LSCF}) / \mathrm{Gd}_{0.1} \mathrm{Ce}_{0.9} \mathrm{O}_{1.95}(\mathrm{GDC}) / \mathrm{YSZ}$ interfaces by using a new glass system. The depth profiles of ${ }^{18} \mathrm{O}$ and metal oxide ions were measured at the interfaces, which visualized the diffusion of oxide ion and change of elemental distribution after the isotopic exchange under cathodic polarization $\left(J=-0.071 \mathrm{Acm}^{-1}\right) .{ }^{18} \mathrm{O}$ concentration peak was identified only under cathodic polarized condition. The ${ }^{18} \mathrm{O}$ peak position was corresponded to the peak of Sr-condensed layer with SIMS and SEM/EDX analyses, where $\mathrm{SrZrO}_{3}$ was formed at the $\mathrm{Gd}_{0.1} \mathrm{Ce}_{0.9} \mathrm{O}_{1.95} / \mathrm{YSZ}$ interfaces. The $\mathrm{SrZrO}_{3}$ formation and ${ }^{18} \mathrm{O}$ profile pile up are correlated due to the increase of ${ }^{18} \mathrm{O}$ incorporation and diffusion of ${ }^{18} \mathrm{O}^{2-}$ though the LSCF cathode.

\section{Acknowledgements}

Part of this study was financially supported by CREST, JST, Japan.

\section{References}

1. B. C. H. Steele and A. Heinzel, Nature 414 (2001) 345-352.

2. F. H. van Heuveln, H. J. M. Bouwmeester, and F. P. F. van Berkel, J. Electrochem. Soc., 144 (1997) 126-133.

3. A. Esquirol, N. P. Brandon, J. A. Kilner, M. Mogensen, J. Electrochem. Soc., 151 (2004) A1847-1855.

4. A. Esquirol, J. A. Kilner, N. P. Brandon, Solid State Ionics, 175 (2004) 63-67.

5. S. P. Jiang, J. Mater. Sci., 43 (2008) 6799-6833.

6. R. Radhakrishnan, A. V. Virkar, S. C. Singhal, J. Electrochem. Soc., 152 (2005) A210-A218.

7. Y. Lu, C. Kreller, S. B. Adler, J. Electrochem. Soc. 156 (2009) B513-B525.

8. T. Horita, T. Shimonosono, H. Kishimoto, K. Yamaji, M. E. Brito, Y. Hori, H. Yokokawa, Electrochemical and Solid-State Letters, 13 (2010) B135-B138. 
9. T. Horita, D.-H. Cho, T. Shimonosono, H. Kishimoto, K. Yamaji, M. E. Brito, H. Yokokawa, J. Electrochem., Soc., 159 (2012) F476-F481.

10. T. Horita, T. Shimonosono, H. Kishimoto, K. Yamaji, M. E. Brito, H. Yokokawa, Solid State Ionics, 225 (2012) 141-145.

11. R. J. Chater, S. Carter, J. A. Kilner, B. C. H. Steele, Solis State Ionics, 53-56 (1992) 859-867.

12. P. S. Manning, J. D. Sirman, J. A. Kilner, Solid State Ionics, 93 (1997) 125-132.

13. E. S. Raj, A. Atkinson, J. A. Kilner, Solid State Inonics, 180 (2009) 952-955

14. M. Rohnke, J. Janek, J. A. Kilner, R. J. Chater, Solid State Ionics, 166 (2004) 89-102.

15. J. A. Kilner, R. A. De Souza, I. C. Fullarton, Solid State Ionics, 86-88 (1996) 703-709.

16. J. A. Kilner, Solid State Ionics, 129 (2000) 13-23.

17. J. A. Lane, S. J. Benson, D. Waller, J. A. Kilner, Solid State Ionics, 121 (1999) 201-208.

18. M. Finsterbusch, A. Lussier, J. A. Schaefer, Y. U. Idzerda, Solid State Ionics 212 (2012) $77-80$.

19. E. Bucher, W. Sitte, F. Klauser, E. Bertel, Solid State Ionics, 191 (2011) 61-67.

20. J. Fleig, Physical Chemistry Chemical Physics, 11 (2009) 3144-3151. 


\section{Figure Captions}

Fig.1 Schematic diagram of ${ }^{16} \mathrm{O} /{ }^{18} \mathrm{O}$ exchange glass apparatus under cathodic polarization.

Fig.2 Back scattered scanning electron microscope (SEM) images of cathode/interlayer/electrolyte interfaces before (a) and after ${ }^{16} \mathrm{O} /{ }^{18} \mathrm{O}$ exchange under cathodic polarization (b).

Fig.3 Current density $(J)$-voltage $(E)$ characteristics of cathode/interlayer/electrolyte interfaces at different temperatures.

Fig.4 SIMS depth profiles of cathode/interlayer/electrolyte after the ${ }^{16} \mathrm{O} /{ }^{18} \mathrm{O}$ exchange under cathodic polarization with cathodic current of $J=-0.071 \mathrm{Acm}^{-2}$, at $973 \mathrm{~K}$. [(a): ${ }^{18} \mathrm{O}$ distribution, (b): metal oxide distribution]

Fig.5 SIMS depth profiles of ${ }^{18} \mathrm{O}$ and cations [(b) and (c)] around the cathode/interlayer /electrolyte interfaces between cathodic polarization and non-polarized condition.

Fig.6 Elemental distribution maps at the cathode/interlayer/electrolyte interfaces. 
Fig.1, T. Horita et al.

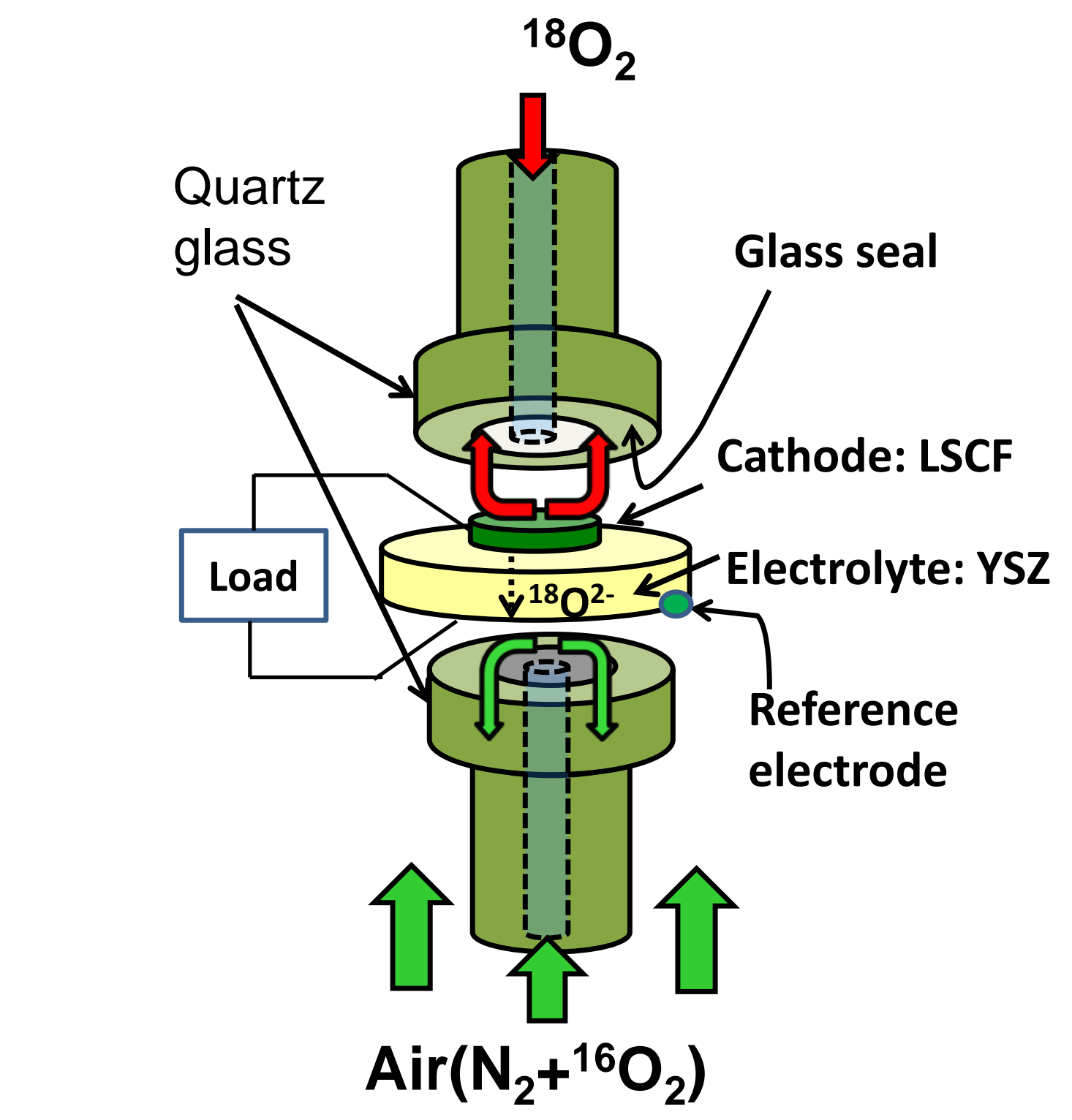

Fig.1 Schematic diagram of ${ }^{16} \mathrm{O} /{ }^{18} \mathrm{O}$ exchange glass apparatus under cathodic polarization 
Fig.2, T. Horita et al.

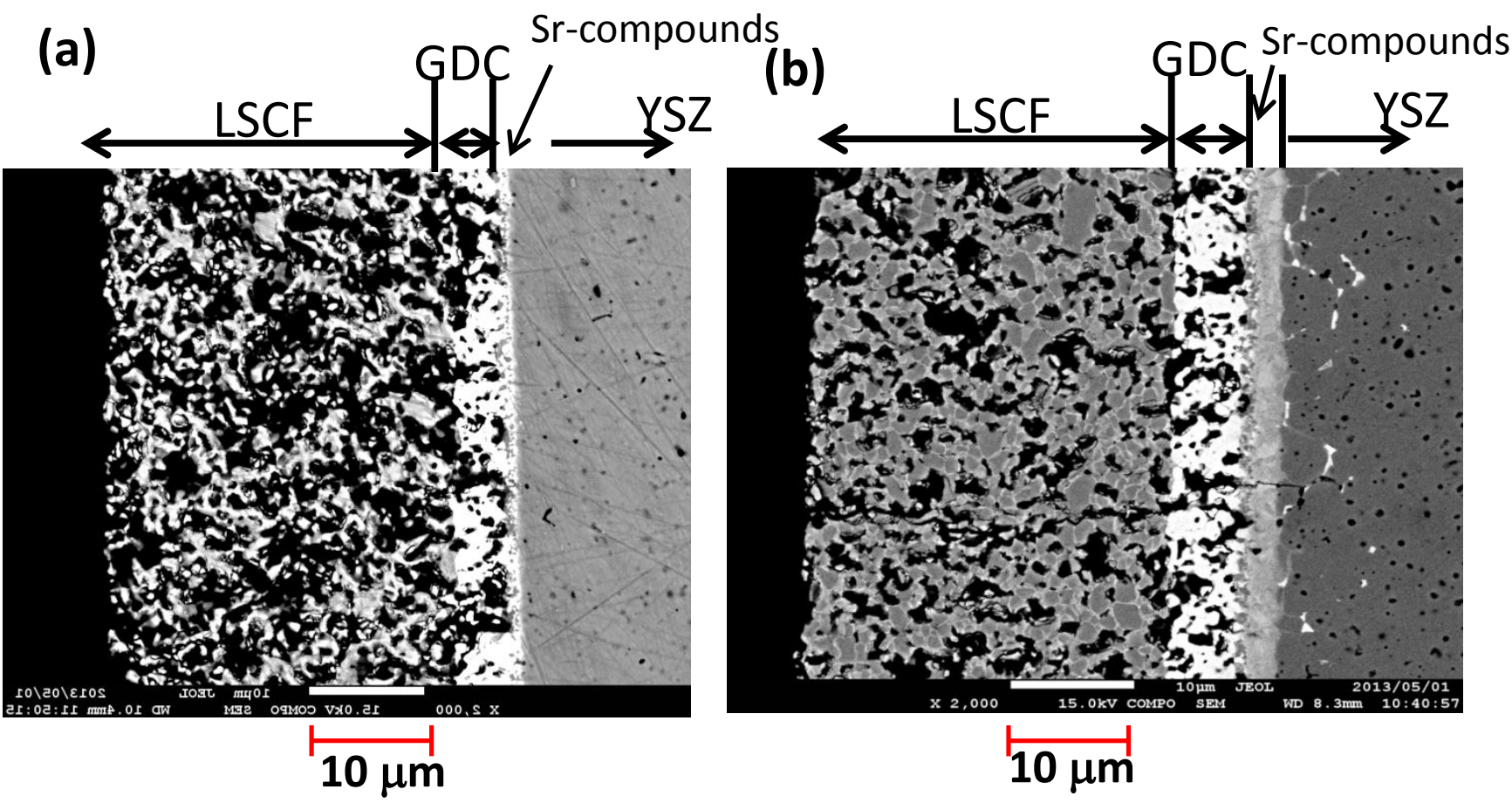

Fig.2 Back scattered scanning electron (SEM) microscope images of cathode/interlayer/electrolyte interfaces before (a) and after ${ }^{16} \mathrm{O} /{ }^{18} \mathrm{O}$ exchange under cathodic polarization (b). 
Fig.3, T. Horita et al.

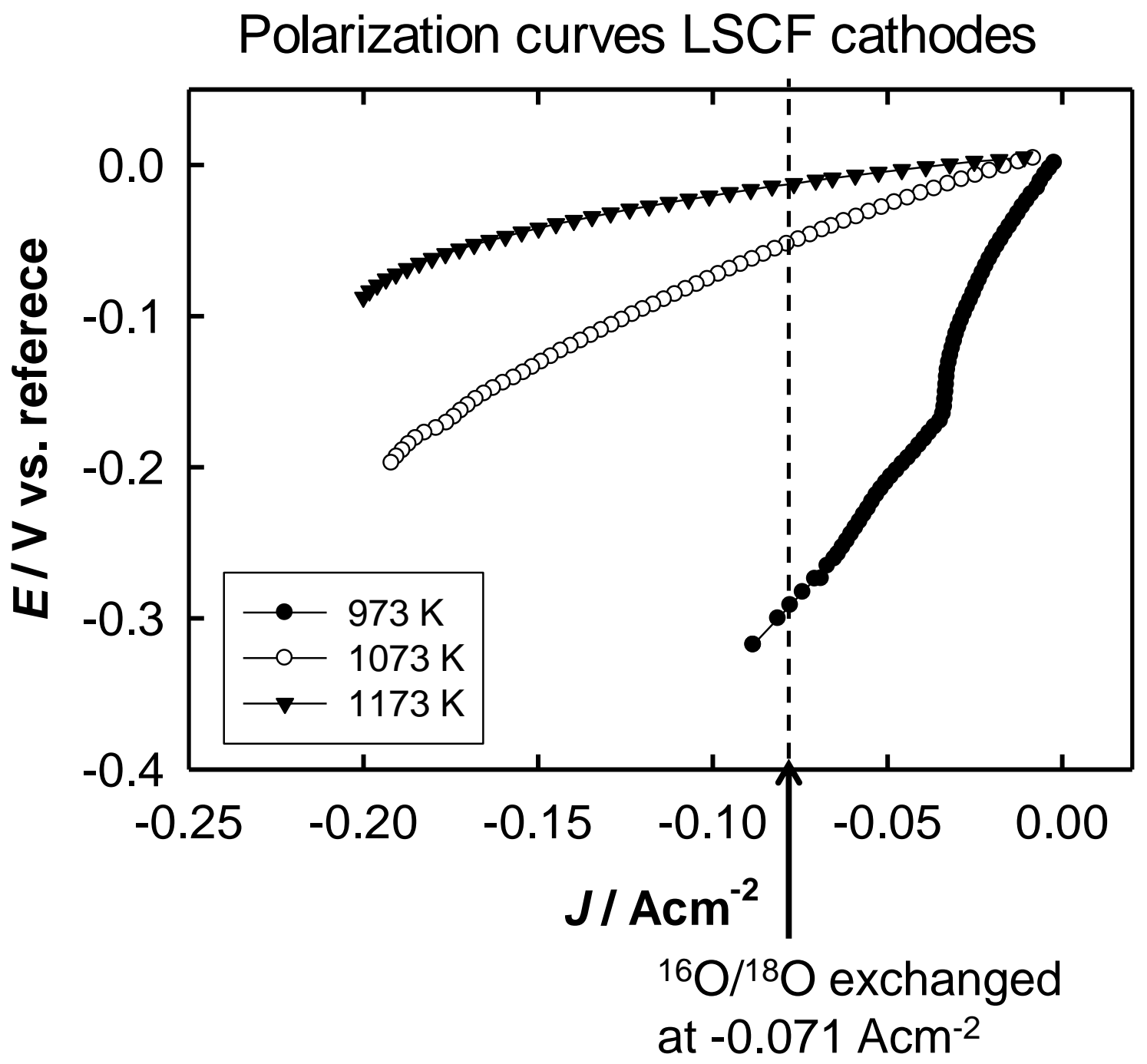

Fig.3 Current density $(J)$ - voltage $(E)$ characteristics of cathode/interlayer/electrolyte interfaces at different temperatures. 
Fig.4, T. Horita et al.

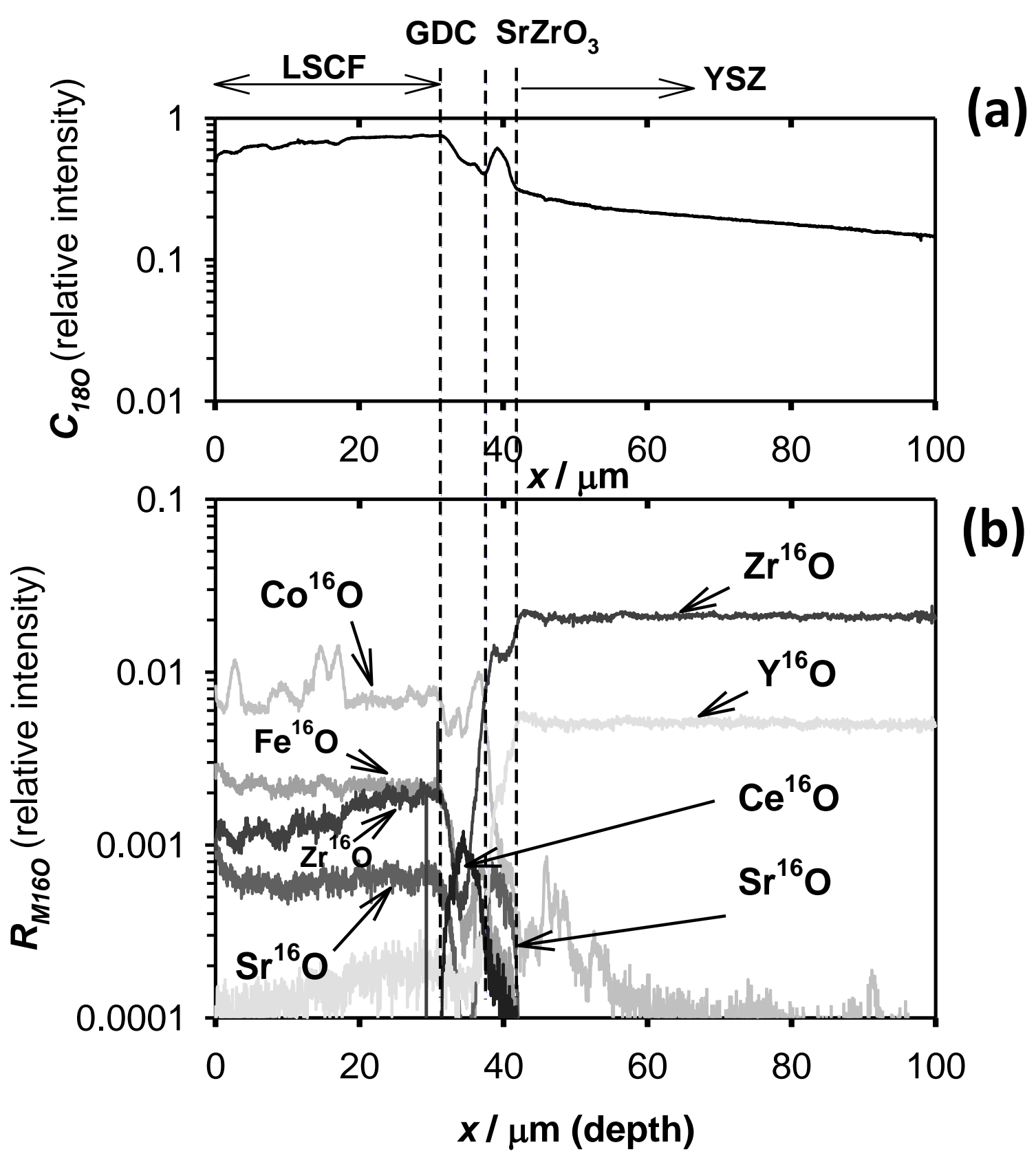

Fig.4 SIMS depth profiles of cathode/interlayer/electrolyte after the 160/180 exchange under cathodic polarization with cathodic current of $\mathrm{J}=-0.071 \mathrm{Acm}-2$, at $973 \mathrm{~K}[(\mathrm{a}): 180$ distribution (b): metal oxide distribution] 
Fig.5, T. Horita et al.

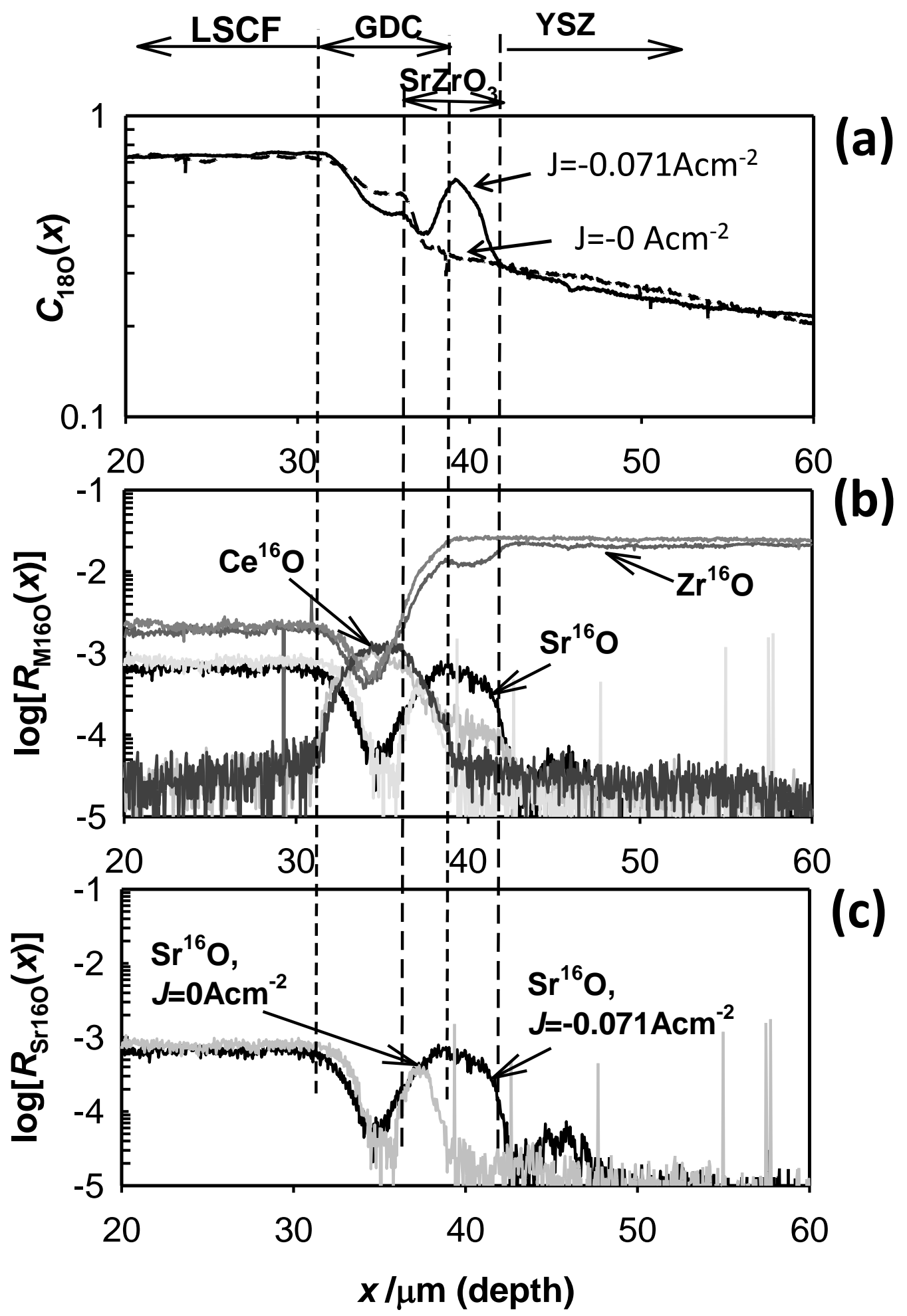

Fig.5 Depth profiles of 180 (a) and metal oxides [(b) and (c)] around the cathode/interlayer /electrolyte interfaces between polarization and non-polarized condition. 
Fig.6, T. Horita et al.
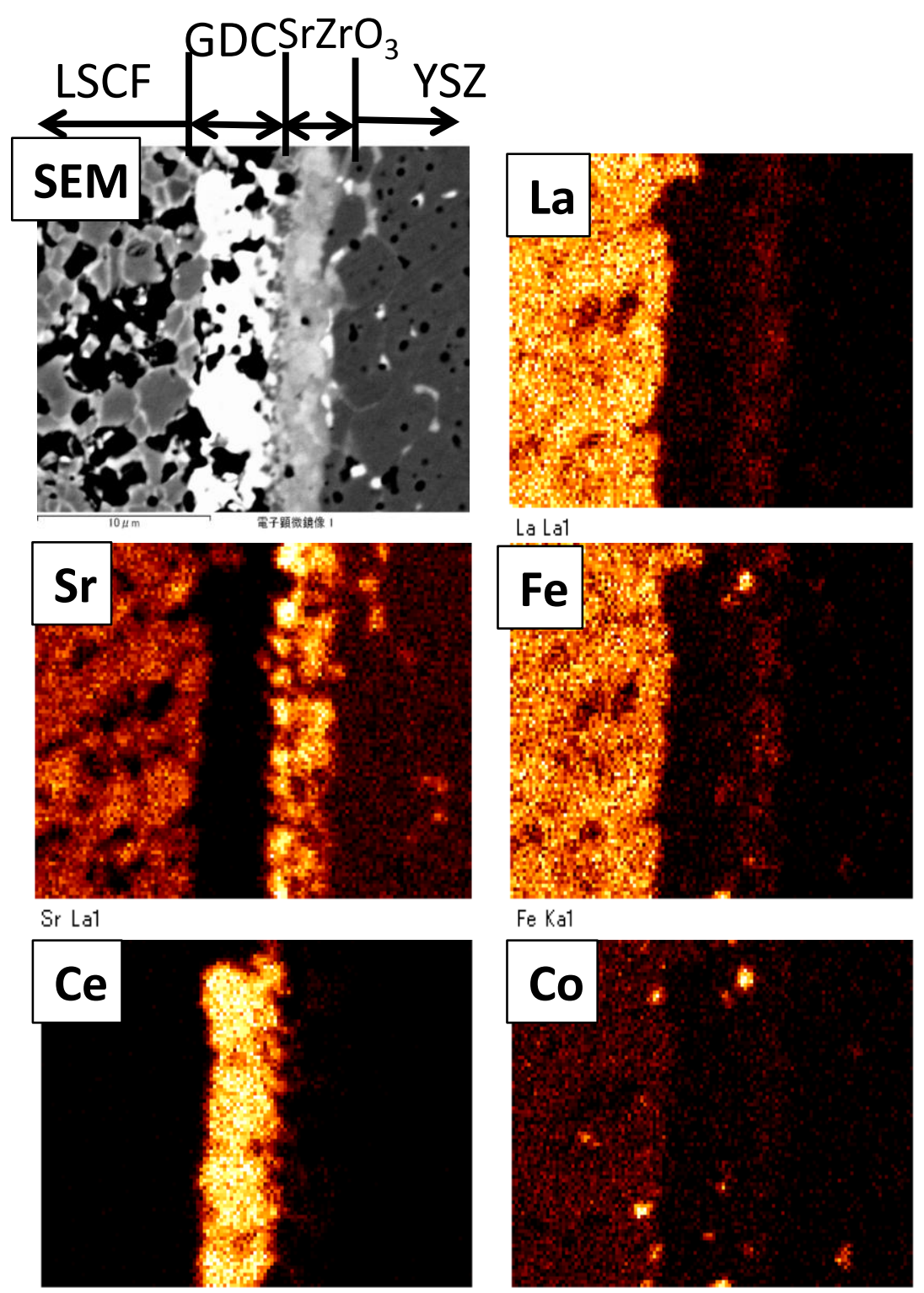

Fe Ka1
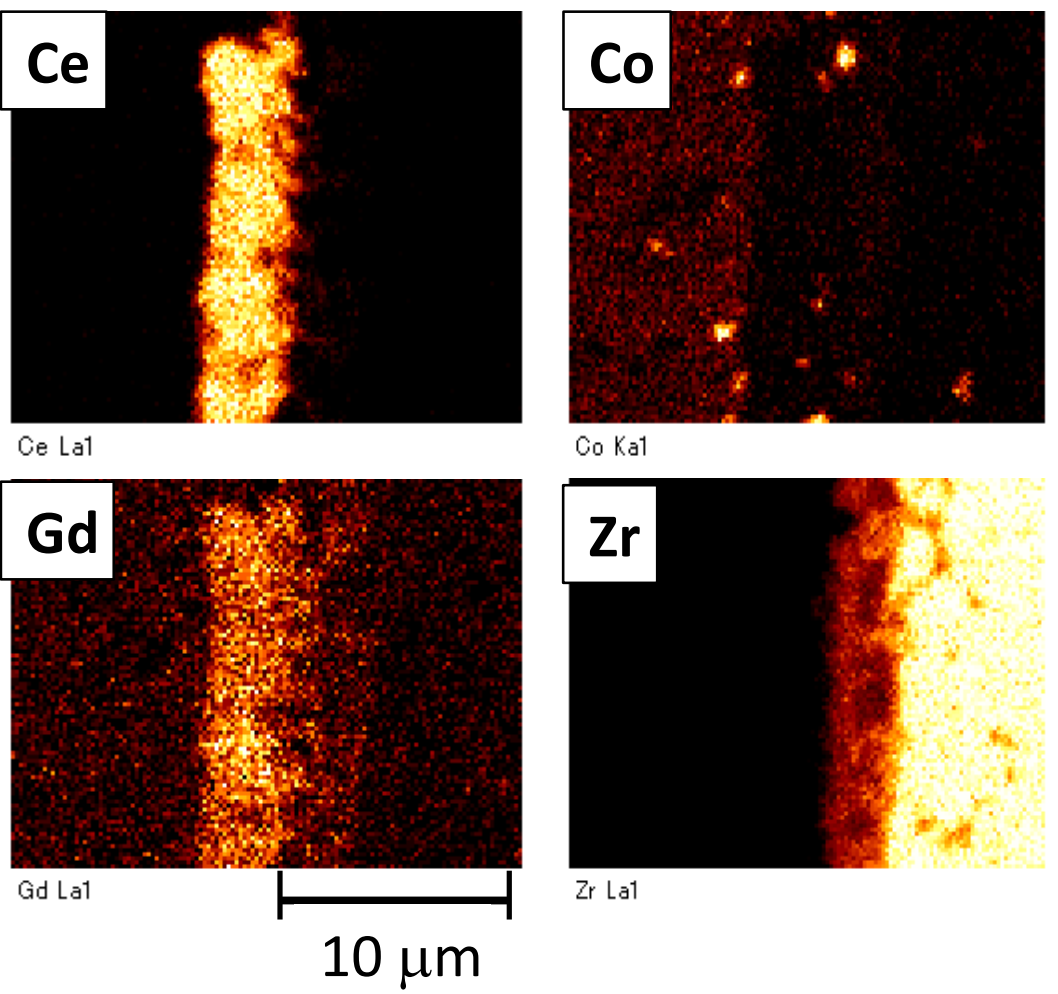

Co Kal

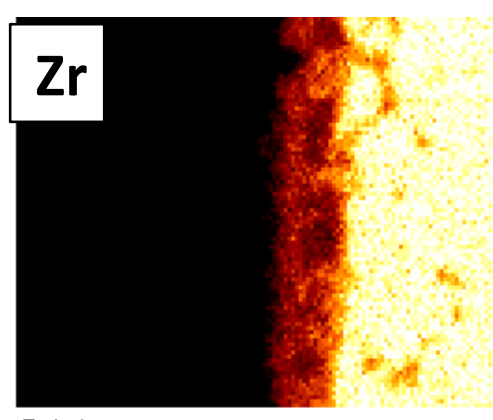

Zr La1

Fig.6 Elemental distribution maps at the cathode/interlayer/electrolyte interfaces. 